\title{
PEMBERDAYAAN NAPI PEREMPUAN LAPAS WAY HUI MELALUI KERAJINAN RAJUTAN DAN PERHITUNGAN PENENTUAN HARGA JUAL PRODUK
}

\author{
Halimah$^{1}$, Sushanty Saleh ${ }^{2}$, Pebrina Swissia ${ }^{3}$ \\ ${ }^{1}$ Fakultas Ilmu Komputer, Informatics \& Business Institute Darmajaya \\ ${ }^{2}$ Fakultas Ilmu Komputer, Informatics \& Business Institute Darmajaya \\ ${ }^{3}$ Fakultas Ilmu Ekonomi \& Bisnis, Informatics \& Business Institute Darmajaya \\ J1. Z.A. Pagar Alam No. 93, Bandar Lampung - Indonesia 35142 \\ Telp. (0721) 787214 Fax. (0721) 700261 \\ e-mail : halimahyunus@darmajaya.ac.id, sushantysaleh@darmajaya.ac.id, pebrinadarmajaya@gmail.com
}

\begin{abstract}
Female prisoners in these prisons become prisoners because they are entangled in various types of criminal law with various crimes committed by women such as due to many factors, leading to reasons for fulfilling the needs of those concerned. For this reason, there is a need for guidance for female prisoners as a form of self-empowerment to improve human resources in the form of life skills. Coaching skills provided by the Proposal Community Procurement team, namely training in the form of handicraft knitting. Knitted handicrafts that have been produced by inmates at the A Way Hui class II prisons include prayer hats, cellphone wallets, restleting wallets, and various kinds of brooches. Knitted products have a fairly high exclusivity value. These female prisoners are expected to succeed in making / producing creative and innovative knitted works seen from various aspects, namely aspects of material selection aspects, in addition the female prisoners are also given training to determine the cost of production and cost of goods sold from their knits.
\end{abstract}

Keywords: Class IIA LAPAS, knitwear, prisoners

\section{PENDAHULUAN}

Narapidana perempuan di lembaga pemasyarakatan ini menjadi warga binaan pemasyarakatan karena terjerat pelbagai macam hukum pidana dengan bermacammacam tindak kriminalitas yang dilakukan oleh perempuan seperti disebabkan karena banyak faktor, hingga berujung alasan karena pemenuhan kebutuhan bagi yang bersangkutan. Adapun alasan lain salah satunya karena masih rendahnya kualitas sumber daya perempuan, yang mengakibatkan termarginalnya perempuan dalam dunia kerja karena dianggap tidak penting [1]. Hal yang mendasar dari penyebab semua tindak kriminalitas tak lain adalah terkait dengan terkikisnya nilai-nilai yang dianut oleh pribadi narapidana [2].

Untuk itu perlunya adanya pembinaan bagi para narapidana perempuan sebagai wujud pemberdayaan diri mereka untuk meningkatkan sumber daya manusia yang berupa keterampilan hidup serta sebagai alat untuk memperbaiki moral bagi narapidana yang bersangkutan. Pada umumnya pembinaan yang dilakukan pada narapidana perempuan di lembaga pemasyarakatan ada dua macam, yaitu pembinaan kepribadian dan kemandirian [2]. Wujud dari pembinaan kepribadian dalam bentuk pembinaan rohani, jasmani dan intelektual. Sedangkan pembinaan kemandirian dalam bentuk keterampilan. Setiap individu memiliki hak mendapatkan pembinaan dalam hal pendidikan dan keterampilan yang merupakan salah satu hak di antara hak kemanusiaan, tidak terkecuali para narapidana pada Lembaga Pemasyarakatan Perempuan kelas II A Perempuan Provinsi Lampung.

Salah satu pembinaan keterampilan yang akan diberikan oleh para tim pengusul Pengadian 
Kepada Masyarakat yakni pembinaan ketrampilan rajutan berupa handicraft, alat sholat, tas, dompet dan bentuk kreasi lainnya. Produk hasil rajutan mempunyai nilai esklusivitas yang cukup tinggi [3]. Apalagi dari segi harga tidak jauh beda bahkan untuk besar kecil ukuran produk menentukan harga produk tersebut semakin mahal karna dilihat dari tingkat kesulitan dalam membuatnya yang semua dikerjakan dengan tangan bukan mesin. Mengapa ketrampilan rajutan ini diberikan pada narapidana pada Lapas Perempuan Kelas II A Perempuan Way Hui Bandar Lampung, karna diharapkan setelah terbebas dari Lembaga Permasyarakatan mereka memiliki ketrampilan yang dapat dijadikan peluang bisnis untuk membantu menambah penghasilan keluarga dan yang tak kalah penting menambah kepercayaan mantan narapidana tersebut di mata masyarakat luar bahwa mereka bisa berkarya dan lebih berguna di lingkungan masyarakat.

Lokasi penelitian adalah LAPAS Perempuan Kelas IIA Way Hui Sukarame Bandar Lampung, yaitu rumah yang digunakan untuk memasyarakatkan warga binaan yang belum ataupun sudah divonis bersalah dalam tindakan pidana yang dilakukan.

\section{IDENTIFIKASI MASALAH}

Pembinaan kepribadian dan kemandirian bukan hanya tanggung jawab pihak pemerintah dalam hal ini pihak lembaga pemasyarakatan saja, namun semua warga negara mempunyai kewajiban untuk memberikan pembinaan kepada para narapidana pada LAPAS Perempuan, dan setiap warga negara juga mempunyai hak untuk memperoleh pembinaan ketrampilan dan hidup layak karena merupakan hak asasi manusia yang diatur dalam Undang undang. Sering ditemui di lingkungan masyarakat, para mantan narapidana perempuan pasca hukuman mereka dipandang hina dan dianggap sebagai sampah masyarakat.

Program pengabdian yang dilakukan di LAPAS Perempuan Kelas II A ini ditargetkan agar para narapidana perempuan pasca hukuman mempunyai ketrampilan yang dapat dijadikan peluang bisnis, dan juga mengikis kurang percaya diri mereka menghadapi tantangan di luar lembaga pemasyarakatan nantinya. Secara khusus, target program dapat kami jelaskan sebagai berikut:

1. Para narapidana perempuan ini berhasil membuat/memproduksi hasil karya rajutan yang kreatif dan inovatif dilihat dari berbagai aspek:

- Aspek pemilihan bahan; benang yang dipakai sebagai bahan rajutan adalah benang yang memang khusus untuk merajut, sehingga kualitas benang akan bagus.

- Aspek warna ; perpaduan warna yang serasi dan selaras

- Aspek model ; produk rajutan bervariasi dalam model, seperti ada beberapa model rajutan aneka bros , dompet restleting, tempat handphone, peci sholat, sampai syal.

2. Para narapidana perempuan mampu menentukan harga pokok produksi serta perhitungan harga jual produk rajutan yang mereka buat.

3. Dapat mengembangkan networking pemasaran melalui pemasaran secara online dengan memperkenalkan $e$ commerce kepada para warga binaan (narapidana).

\section{METODELOGI PELAKSANAAN}

Kegiatan ini dilaksanakan dengan cara Pelatihan dan pendampingan, seperti pada bagan berikut : 


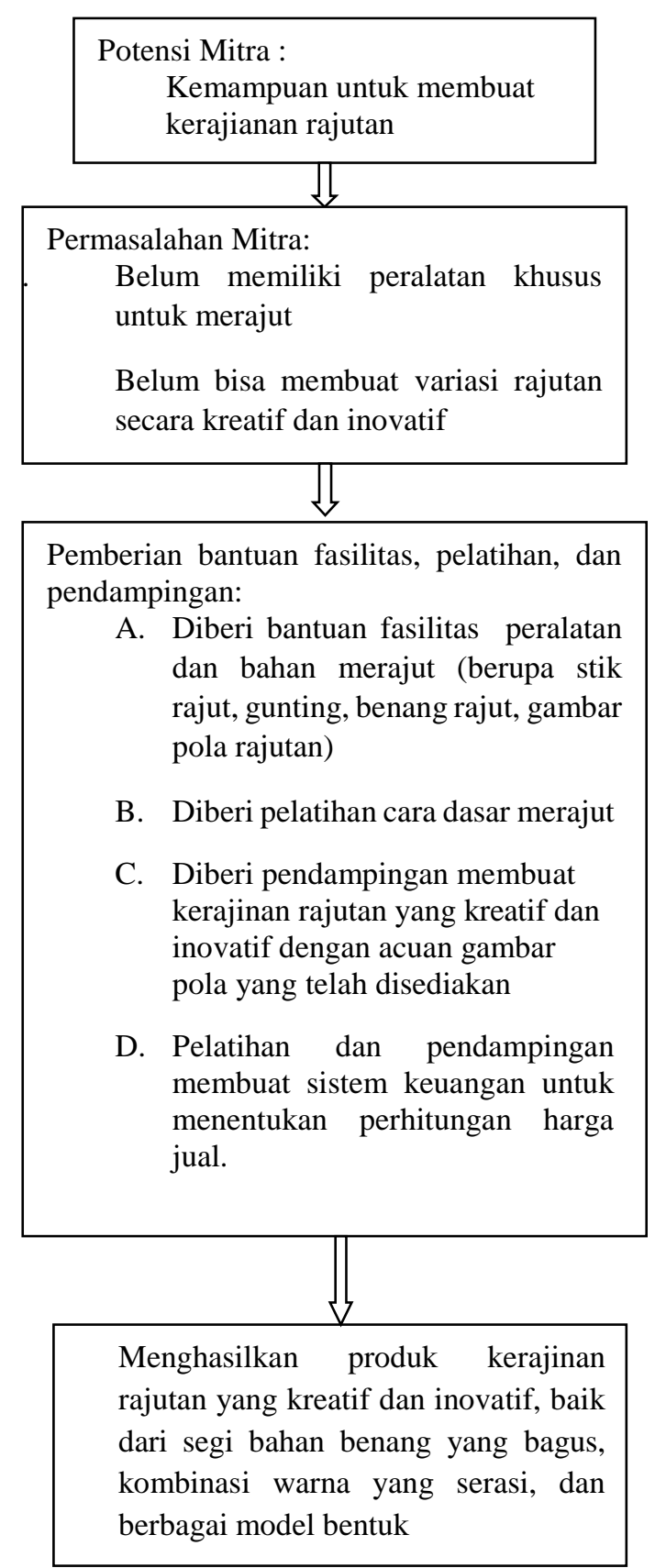

\section{HASIL DAN PEMBAHASAN}

Langkah pertama yang dilakukan kami adalah melakukan rapat koordinasi dengan tim membahas langkah-langkah yang akan dilakukan untuk memberikan pelatihan membuat rajutan, penentuan harga pokok produksi dan penjualan bagi warga binaan pada lapas perempuan kelas IIA Way Hui Bandar Lampung. Kegiatan ini dilaksanakan 3 tahapan yaitu, 1. Persiapan kegiatan, 2. pelaksanaan kegiatan dan 3. pembuatan laporan.

\section{A. Persiapan Kegiatan}

Langkah awal yang harus kami lakukan adalah melakukan persiapan kegiatan. Persiapan kegiatan meliputi 5 sub kegiatan yaitu : (1). Koordinasi tim pelaksana pengabdian masyarakat, (2) Pengurusan surat ijin ke lapangan, (3) Koordinasi dengan calon peserta pelatihan, (4) Mencari pelatih untuk kegiatan pelatihan merajut (5) Mempersiapkan bahan bahan untuk kegiatan pelatihan.

Berikut, adalah rincian kegiatan persiapan yaitu

1. Koordinasi tim pelaksana pengabdian masyarakat : Hal pertama yang dilakukan adalah rapat koordinasi tim pelaksana kegiatan pengabdian masyarakat. Rapat dihadiri oleh ketua, anggota, dan 1 orang mahasiswa untuk membantu kelancaran kegiatan ini. Dalam rapat koordinasi ini dibahas tentang teknis pelaksanaan kegiatan, jadual pelaksanaan, dan mencari informasi tentang instruktur yang memiliki keahlian merajut.

2. Pengurusan surat ijin ke lapangan; Pada tahap kedua ini dilakukan pengurusan ijin ke lapangan agar kegiatan yang dilaksanakan berjalan lancar tanpa kendala. Pengurusan ijin ke lapangan dengan meminta surat tugas yang dterbitkan dari lembaga LP4M (Lembaga Pelatihan,Pengembangan, Penelitian, Pengabdian Kepada masyarakat) yang ada pada institusi kami Institut Informatika dan Bisnis Darmajaya.

3. Koordinasi dengan calon peserta pelatihan dan pihak lapas perempuan kelas II A Way hui pada bidang kegiatan kerja ; Pada tahap ketiga, dilakukan koordinasi dengan calon peserta pelatihan. Tim kegiatan pengabdian masyarakat mendatangi lokasi LAPAS Perempuan Kelas II A tempat calon peseta pelatihan. Pada pertemuan ini dibahas tentang teknis pelaksanaan kegiatan termasuk jadual kegiatan dan lokasi kegiatan serta banyaknya warga binaan yang akan mendapat pelatihan dari kami tim 
pengabdi. Kegiatan pelatihan merajut dan penentuan harga pokok produksi dan penjualan dilaksanakan sebanyak 3 kali pertemuan, dengan setiap pertemuan selama 8 jam.

4. Mencari pelatih untuk kegiatan pelatihan merajut Pada tahap ke empat ini, tim pelaksana kegiatan pengabdian masyarakat mencari instruktur yang memiliki keahlian di bidang keterampilan merajut

5. Mempersiapkan bahan - bahan untuk kegiatan pelatihan ; Pada tahap terakhir dilakukan pengadaan barang-barang yang akan digunakan pelatihan. Bahanbahan yang dibeli untuk pelatihan merajut misalnya benang rajut, jarum, bahan alas, assesoris, dan penyiapan pola.Pengadaan bahan rajutan langsung dbeli oleh tim pengabdi dan instruktur.

\section{B. Pelaksanaan Kegiatan}

Pelaksanaan Kegiatan dilaksanakan pada LAPAS Perempuan Kelas II A Way Hui Bandar Lampung. Kegiatan pertama yang dilaksanakan adalah pelatihan ketrampilan merajut sedangkan kegiatan kedua berupa pelatihan pembuatan sistem keuangan menentukan perhitungan harga jual. Kegiatan diikuti 20 peserta warga binaan pada Lapas Perempuan Way Hui yang dimulai dari jam 8 pagi hingga jam 4 sore.

Adapun rincian dari masing-masing kegiatan adalah sebagai berikut:

\section{Kegiatan Pelatihan Merajut}

\section{Pertemuan Pertama:}

- Pada sesi pertama pelatihan rajutan, peserta diperkenalkan terlebih dahulu bahan-bahan rajutan, seperti 1 . benang rajutan bahan polycherry, 2.jarum rajut(hakpen) 4/5, 3. Benang jahit, 4. Sleting ukuran $20 \mathrm{~cm}, 5$. Manik-manik, 6 . Lem tembak dan isi lem, 7. Peniti bros. Selain itu peserta juga diperkenalkan berbagai contoh bentuk rajutan seperti bros, dompet sleting, tampat handphone, peci sholat, syal.

- Peserta juga diberi pelajaran cara teknis dasar merajut dan cara menggunakan peralatan rajut.

- Peserta diberi pelatihan beberapa jenis tusukan seperti tusukan pola V stitchdouble crochet(dc) untuk dompet HP, single crochet (sc) \& double crochet (dc) untuk dompet sleting, double crochet (dc) untuk peci, dan single crochet (sc) \& double crochet $(\mathrm{dc})$ untuk bros.

\section{Pertemuan kedua :}

- Pada pertemuan kedua peserta diberikan pelatihan membuat bermacam bentuk bros dan dompet hp

- diberikan pelatihan membuat dompet hp

- pelatihan perhitungan harga pokok penjualan kerajian rajutan dan penentuan harga jual.

\section{Pertemuan ketiga}

- Peserta mulai mengembangkan kreativitas mereka dengan membuat rajutan yang memerlukan ketelitian dan ketelatenan seperti syal dan dompet resleting.

- Evaluasi pelatihan rajutan dan perhitungan harga jual. Dilakukan pengecekan rajutan yang sudah dibuat oleh para warga binaan lapas perempuan.

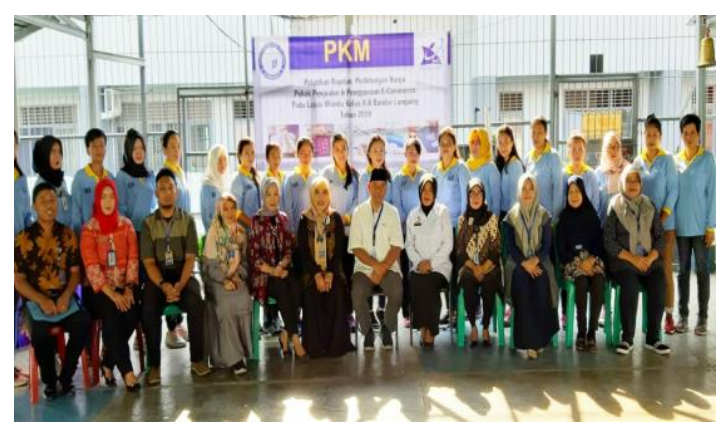

Gambar 1. Pembukaan Pelatihan Rajutan dan Perhitungan Penentuan Harga Jual Barang 


\section{K ptokmas}

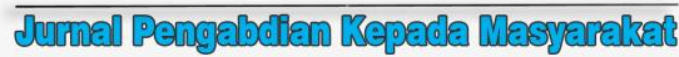

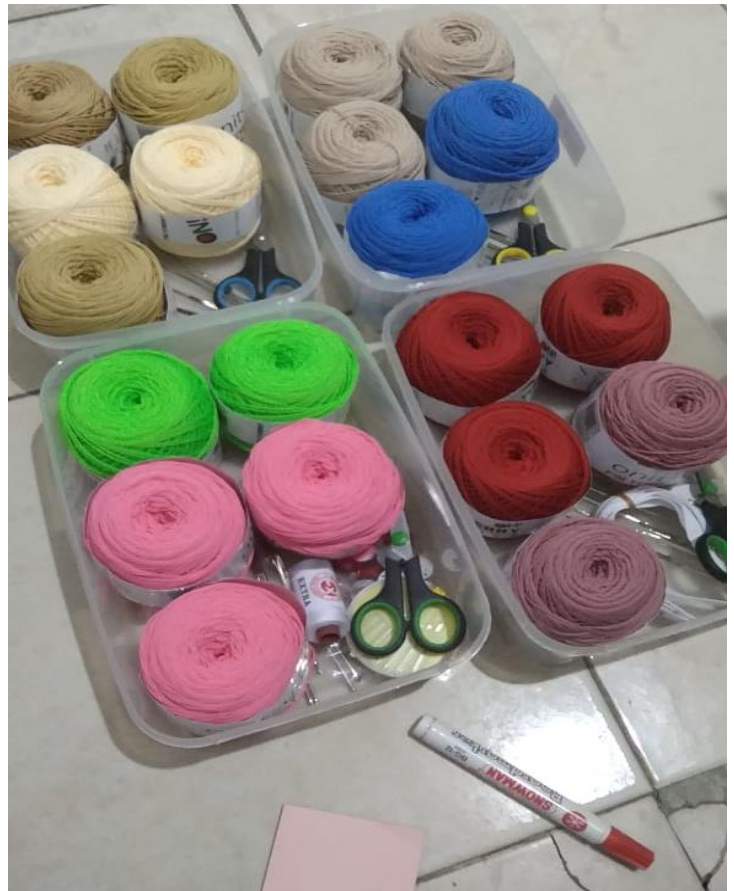

Gambar 2. Benang Rajut Besar

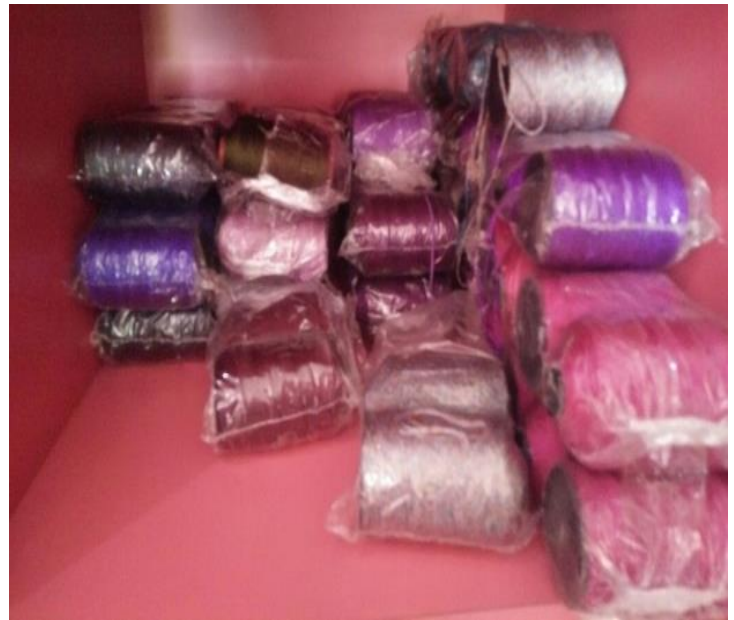

Gambar 3. Benang Halus

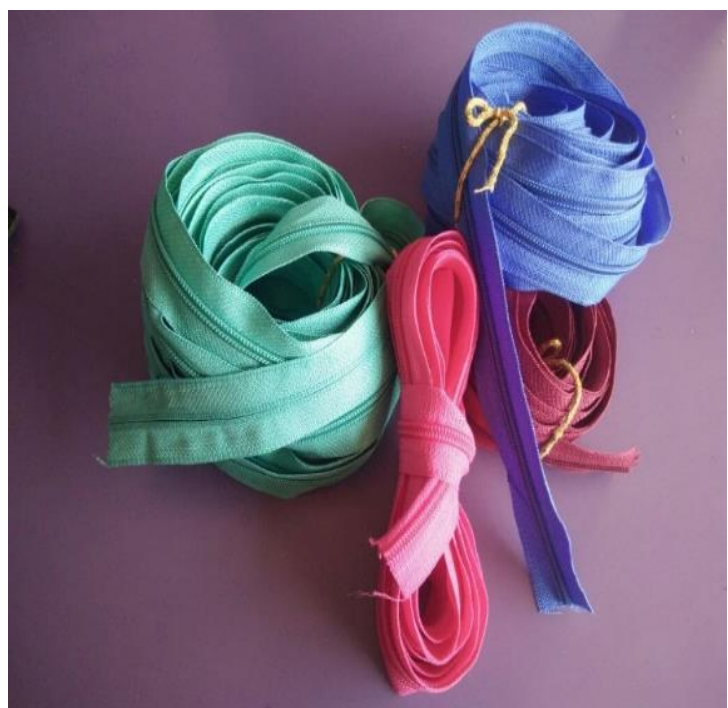

Gambar 4. Resleting

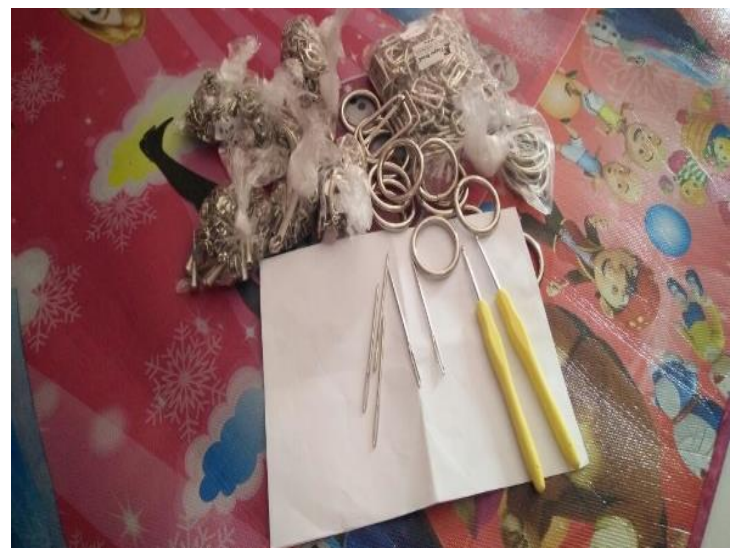

Gambar 5. Peralatan Rajut (Hakpen)

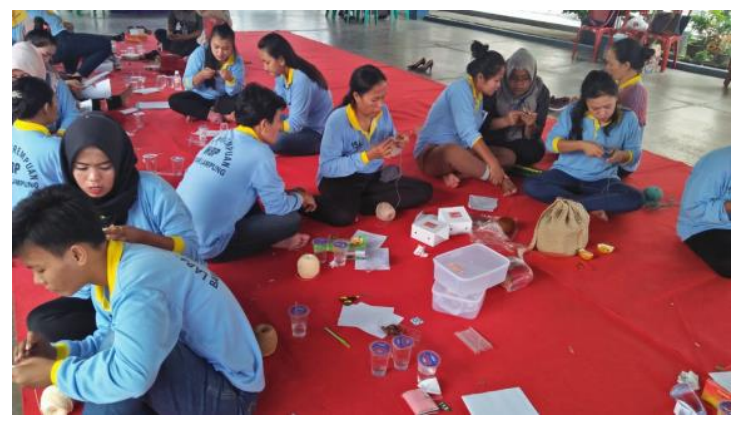

Gambar 6. Kegiatan Merajut 


\section{x ptekmas}
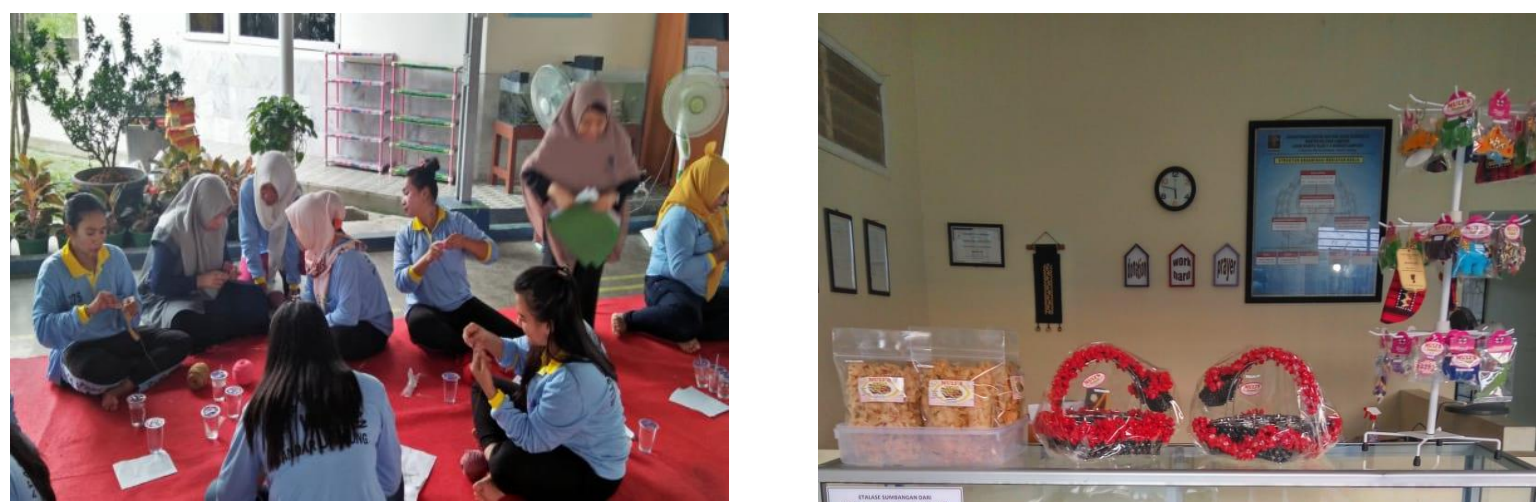

Gambar 7. Kegiatan Merajut
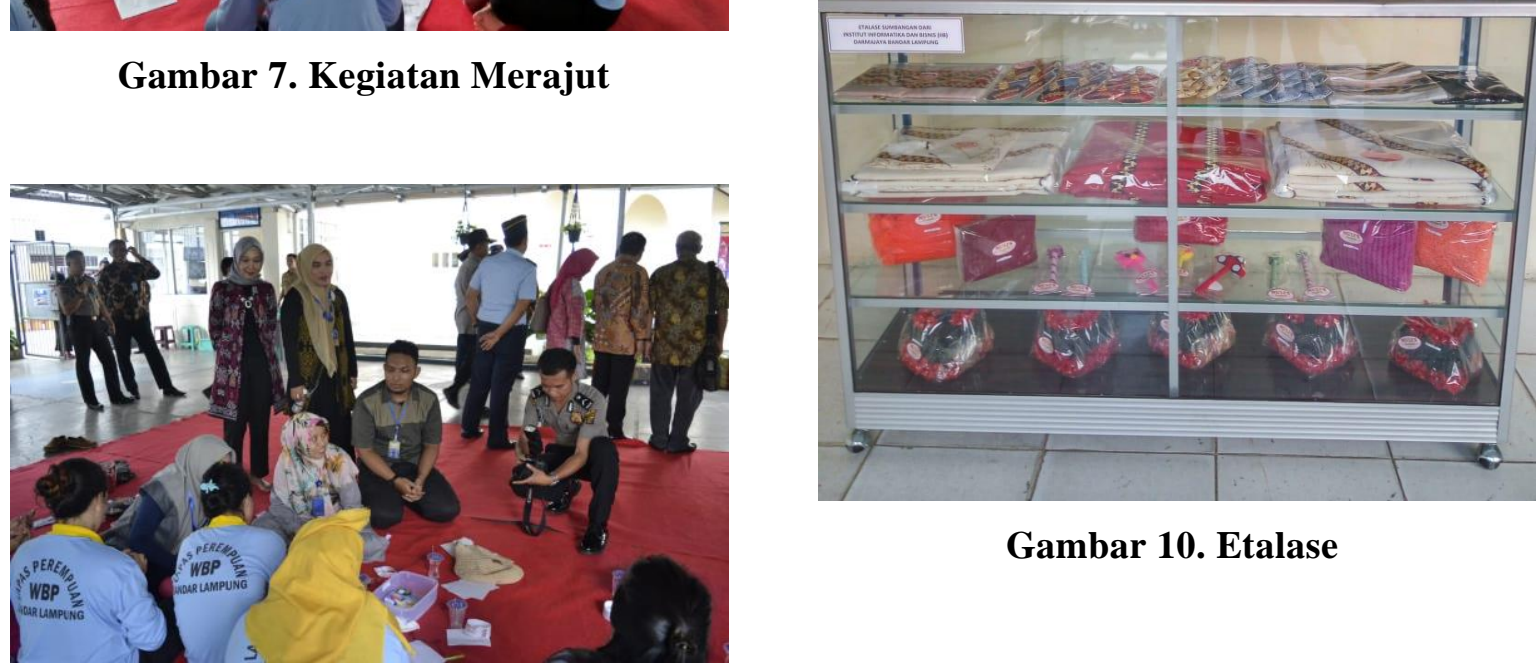

Gambar 10. Etalase

Gambar 8. Kegiatan Merajut

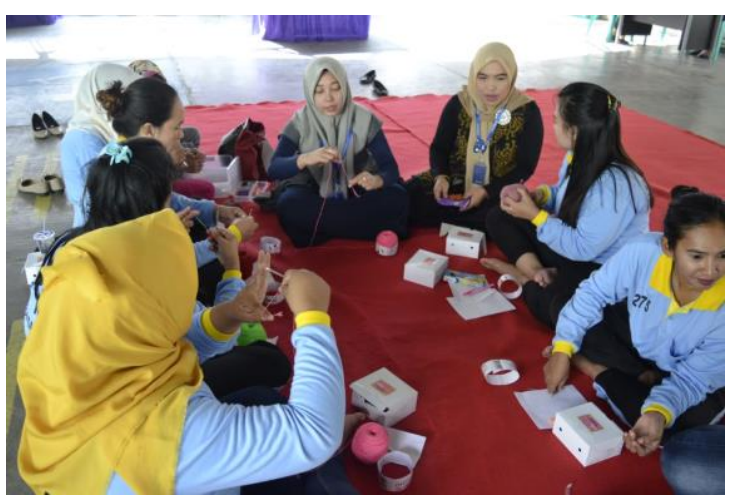

Gambar 9. Kegiatan Merajut

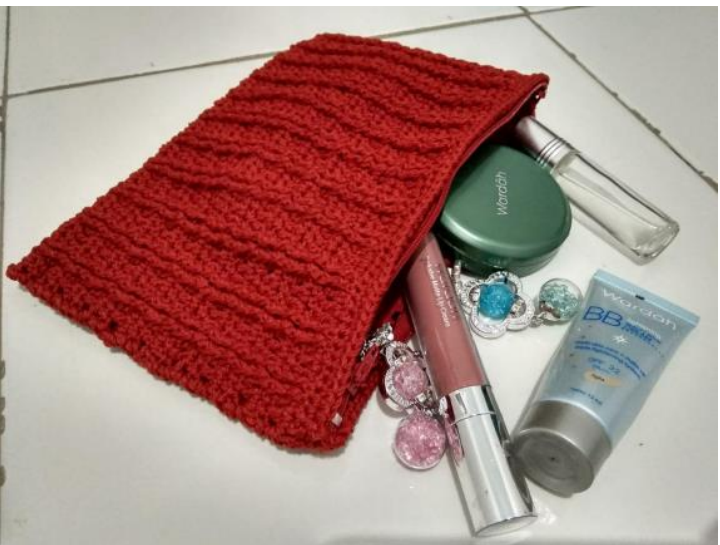

Gambar 11. Dompet Hasil Rajutan 


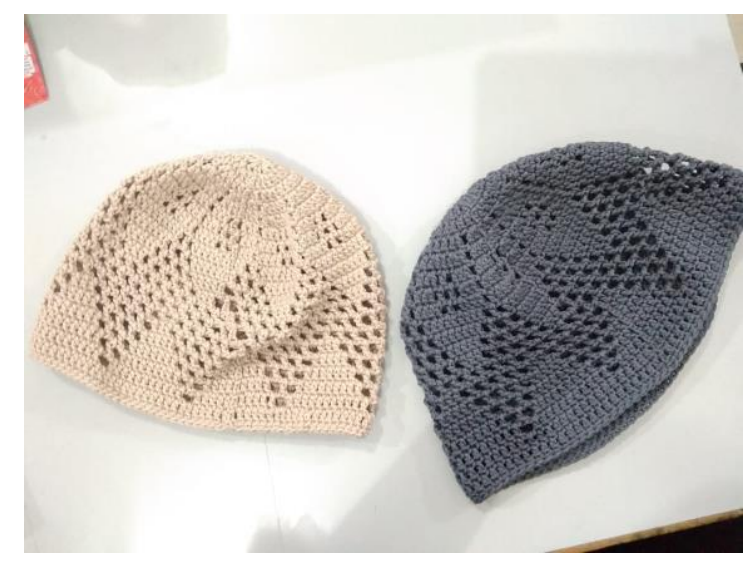

Gambar 12. Peci Hasil Rajutan

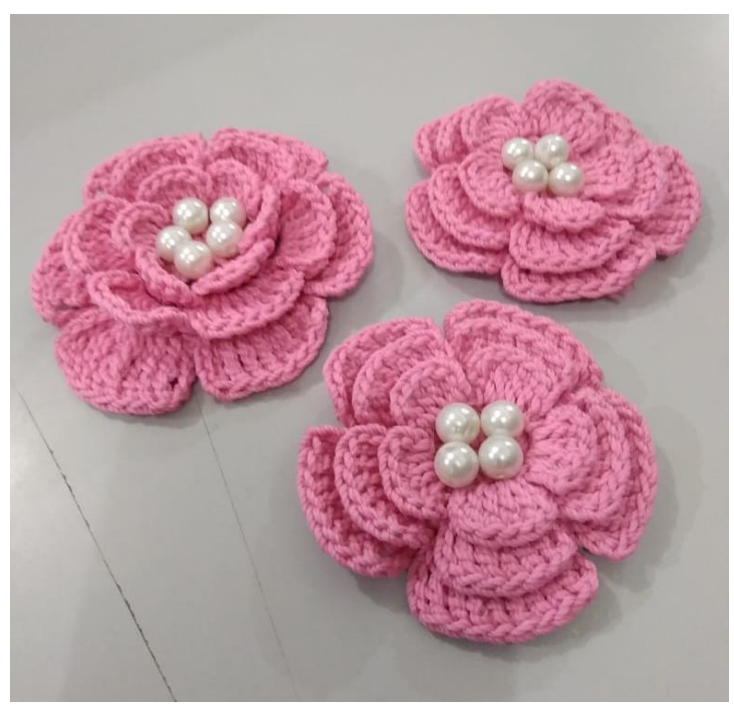

Gambar 12. Bros Hasil Rajutan

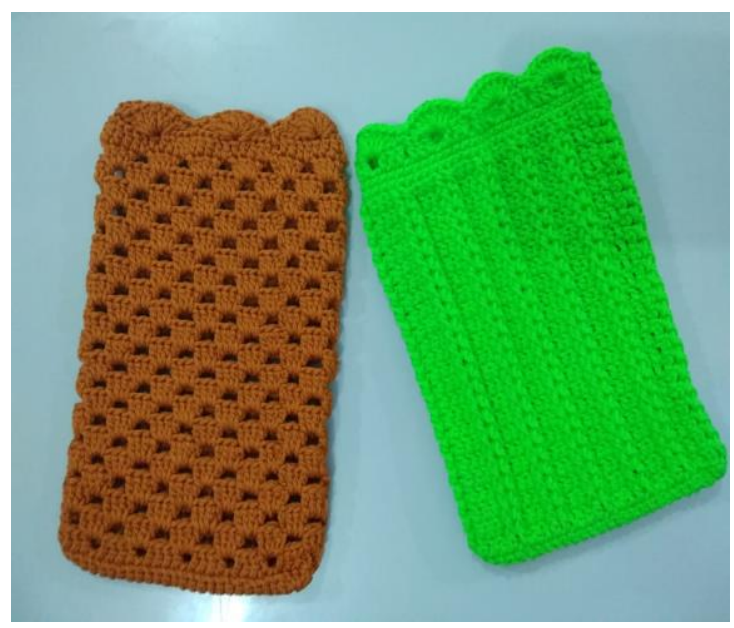

Gambar 13. Dompet HP Hasil Rajutan

\section{KESIMPULAN DAN SARAN}

\subsection{Kesimpulan}

Kesimpulan dari kegiatan ini adalah sebagai berikut :

1. Peserta antusias dalam mengikuti kegiatan pelatihan rajutan dan penentuan harga pokok produksi dan penjualan yang dapat dilihat dari keaktifan mereka mengikuti kegiatan dari pagi hingga sore.

2. Setiap peserta pelatihan dapat membuat aneka rajutan dari bros, peci, dompet dan tempat hp.

3. Peserta juga telah mampu melakukan kalkulasi harga jual dengan menghitung harga bahan sesuai kualitas yang digunakan.

\subsection{SARAN}

Diharapkan untuk kegiatan selanjutnya dapat berjalan lancar dan pelatihan lainnya yang dapat memberikan peningkatan kemampuan dan kreativitas warga binaan pada Lapas Perempuan Way Hui serta untuk membantu warga binaan dalam menambah kepercayaan mantan narapidana tersebut di mata masyarakat luar bahwa mereka bisa berkarya dan lebih berguna di lingkungan masyarakat. Selain itu perlunya kegiatan yang berkelanjutan berupa pemantauan sebagai upaya untuk memastikan bahwa Lapas perempuan Way Hui telah berhasil memasarkan produk yang telah mereka terima selama mengikuti pelatihan.

\section{UCAPAN TERIMA KASIH}

Ucapan terimakasih yang sebesar-besarnya kepada Direktorat Penelitian dan Pengabdian kepada Masyarakat Kementrian Pendidikan Riset dan Teknologi Indonesia yang telah menjadi sponsorship untuk pelaksanaan pengabdian ini.

Ucapan terimakasih juga kami sampaikan kepada Institut Informatika dan Bisnis Darmajaya yang telah memfasilitasi ruang penelitian dan pengabdian bagi dosen pemula sehingga tercapainya kegiatan ini yang dapat diabdikan ke masyarakat. 


\section{REFERENSI}

[1] Erna Setijaningrum, Aris Armuninggar, 2016, Networking Wirausaha Melalui Kerajinan Rajutan Kreatif Dan Pemasaran Online Bagi Mahasiswa STKIP-PGRI Kabupaten Nganjuk Dan STKIP-PGRI Kabupaten Sidoarjo, Universitas Airlangga.

[2] Erna Suryani, 2018, Pembelajaran Keterampilan Batik Sebagai Pemberdayaan Narapidana Perempuan Di Lembaga Pemasyarakatan Perempuan Kelas II B Yogyakarta, Yogyakarta.

[3] TM. Zaini, Halimah, Besti Lilyana, 2018, Kerajinan Limbah Kain Untuk Seni Motif Lampung Dan Peningkatan Ekonomi Untuk Napi Wanita Pada Lapas Wanita
Kelas IIA Way Hui Bandar Lampung. Jurnal Sosioteknologi Kreatif. Vol (2) : 288-295. 